Costs of diabetes medication among male former elite athletes in later life

Laine, M. K.

2017-04

Laine , M K , Kujala , R , Eriksson , J G , Kautiainen , H , Sarna , S \& Kujala , U M 2017 , ' Costs of diabetes medication among male former elite athletes in later life ', Acta

Diabetologica , vol. 54 , no. 4 , pp. 335-341 . https://doi.org/10.1007/s00592-016-0947-9

http://hdl.handle.net/10138/236706

https://doi.org/10.1007/s00592-016-0947-9

publishedVersion

Downloaded from Helda, University of Helsinki institutional repository.

This is an electronic reprint of the original article.

This reprint may differ from the original in pagination and typographic detail.

Please cite the original version. 


\title{
Costs of diabetes medication among male former elite athletes in later life
}

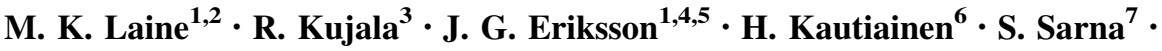 \\ U. M. Kujala ${ }^{8}$
}

Received: 29 September 2016/ Accepted: 21 November 2016/Published online: 8 December 2016

(C) Springer-Verlag Italia 2016

\begin{abstract}
Aims Regular physical activity plays a major role, in both prevention and treatment of type 2 diabetes. Less is known whether vigorous physical activity during young adulthood is associated with costs of diabetes medication in later life. The aim of this study is to evaluate this question.

Methods The study population consisted of 1314 former elite-class athletes and 860 matched controls. The former athletes were divided into three groups based on their active career sport: endurance, mixed and power sports. Information on purchases of diabetes medication between 1995 and 2009 was obtained from the drug purchase register of the Finnish Social Insurance Institution.
\end{abstract}

Managed by Antonio Secchi.

M. K. Laine

merja.k.laine@helsinki.fi

1 Department of General Practice and Primary Health Care, Helsinki University Hospital, University of Helsinki, Tukholmankatu 8 B, PL 20, 00140 Helsinki, Finland

2 Vantaa Health Center, Vantaa, Finland

3 Department of Computer Science, Aalto University, Espoo, Finland

4 Department of Chronic Disease Prevention, National Institute for Health and Welfare, Helsinki, Finland

5 Folkhälsan Research Center, Helsinki, Finland

6 Primary Health Care Unit, Kuopio University Hospital, Kuopio, Finland

7 Department of Public Health, University of Helsinki, Helsinki, Finland

8 Department of Health Sciences, University of Jyväskylä, Jyväskylä, Finland
Results The total cost of diabetes medication per person year was significantly lower among the former endurance (mean $81 €[95 \%$ CI 33-151 €]) and mixed group athletes (mean $272 €[95 \%$ CI 181-388 €]) compared with the controls (mean $376 €$ [95\% CI 284-485 €]), $(p<0.001$ and $p=0.045$, respectively). Of the former endurance athletes, $0.4 \%$ used insulin, while $5.2 \%$ of the controls used insulin $(p=0.018)$.

Conclusions A career as former endurance, sprint, jumper or team game athlete seems to reduce the costs of diabetes medication in later life.

Keywords Cost - Diabetes · Elite-class athlete . Medication · Physical activity

\section{Introduction}

The burden of diabetes is increasing worldwide [1]. Regular physical activity is one of the corner stones in both prevention and treatment of type 2 diabetes [2-7]. Based on previous studies, vigorous physical activity during young adulthood as well as an active lifestyle seems to be associated with a lower prevalence of type 2 diabetes in later life $[8,9]$. Also, it has been shown that structured exercise training consisting of aerobic exercise, resistance training or both combined is associated with better glycemic control in patients with type 2 diabetes [10-12]. However, only little long-term data exist on the optimal timing, intensity and frequency of exercise training in relation to glucose control in patients with type 2 diabetes $[13,14]$. Physical activity has several other favourable effects on an individual's life, for example improved functional status and ameliorated physical fitness [15]. However, less is known whether vigorous physical activity 


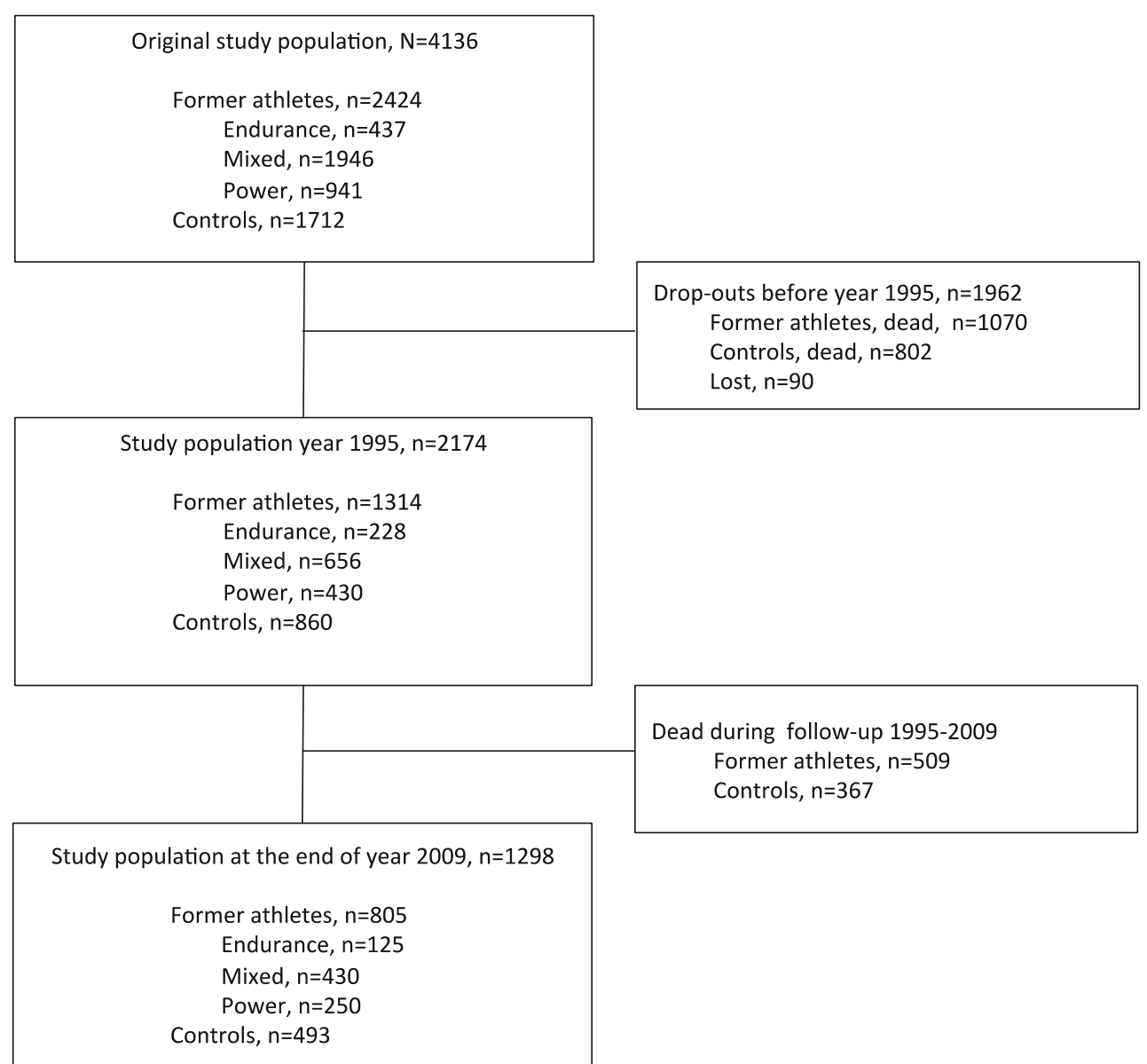

Fig. 1 Flow chart of the study

during young adulthood has any effect on the costs of diabetes medication in later life.

A questionnaire-based study including Finnish male former elite athletes and their matched controls was initiated in 1985 [16]. Male former elite athletes have a documented history of vigorous physical activity in their past, generally spanning from adolescence to late 20 or $30 \mathrm{~s}$. This enables research focusing upon the long-term effects of physical activity on different health-related aspects without the need to actually measure physical activity in young adulthood.

The aim of this study is to evaluate whether a career as an elite-class athlete has any effect on the costs of diabetes medication in later life.

\section{Subjects and methods}

\section{Subjects}

The original study cohort $(N=4136)$ consists of male former elite athletes $(n=2424)$ who represented Finland between the years 1920 and 1965 at least once in international competitions (Olympic games, World or European championships or other inter-country competitions) and their matched controls $(n=1712)$ [16]. The controls were classified as healthy at the medical examination, which all Finnish men undergo at age of 20 years as part of the national military service. Male former elite athletes were divided into three groups according to the type of training needed to achieve optimal results [17]: endurance sports (long- and middle-distance running, cross-country skiing), mixed sports (soccer, ice hockey, basketball, track and field: jumpers, sprinters, hurdles, decathletes) and power sports (boxing, wrestling, weight lifting, track and field throwers).

Those who were alive in the year 1995 when medication data collection was initiated are included in this study; 1314 former elite athletes and 860 controls, in total 2174 individuals (for flow chart, see Fig. 1). One power sport athlete had type 1 diabetes.

\section{Methods}

The outcome of this study comprised of register-based purchases of diabetes medication (Anatomical Therapeutic 
Chemical [ATC] Classification System codes A10A, A10B and A10X) during the years 1995-2009. From the Finnish Social Insurance Institution prescription register, those who purchased any diabetes medications were linked with the athlete cohort; the prescription registry was set up in 1995, and our linkage covered purchases until the end of year 2009. The Finnish Social Insurance Institution provides data on the number of prescriptions a person has purchased during the study period as well as the costs of the medications. In this study, data on diabetes medications including the costs of medications were divided into two classes: insulin (ATC-code A10A) and other diabetes drugs (ATC-codes A10B and A10X) [18].

The cumulative incidence of diabetes was calculated based upon diabetes drug purchases according to the Finnish Social Insurance Institution prescription register and the participants' self-report on diabetes (1995-2009).

The yearly sums of the costs of each medication group (ATC-codes A10A and ATC-codes A10B and/or A10X) were computed for each user and adjusted to correspond to the nominal EURO values in the year 2010. The inflation correction was computed based on the annual averages of the Finnish consumer price index provided by Official Statistics of Finland [19].

In the year 1985, a questionnaire was sent to all living former athletes and their controls [16]. From the questionnaires, we obtained data on self-reported diabetes and occupation. The occupation of each participant was classified according to the one where he has been in most of his lifetime. Based on the Finnish classification of occupations, the participants were grouped into four groups: highly educated (management and professionals), white-collar workers (experts, office workers and clerks), blue-collar workers (service, sales, construction, repair, manufacturing, process and transport workers), and farmers, others or unskilled [20]. There were missing data for 94 participants. Date of death was obtained from the Cause-of-Death Bureau at Statistics Finland.

\section{Statistical analysis}

Data are reported as mean (standard deviations, SD) or number (percentage, \%). Statistical comparisons were made by using analysis of variance (ANOVA) and post hoc testing with Dunnett, or analysis of covariance (ANCOVA) and post hoc testing of several univariate comparisons were made with Hochberg's, adjustment at significance level 0.05. As the data for costs were highly skewed, bias-corrected and accelerated bootstrap estimation was used for statistical comparison and derived 95\% confidence intervals. Time-to-event analysis is based on the product limit estimate of the cumulative 'survival' function. Stata 14.1, StataCorp LP (College Station, TX, USA) statistical package was used for the analyses.

\section{Results}

\section{Response rate and basic characteristics}

The response rate to the questionnaires sent in 1985 was $77.1 \%$ in the whole study population, $82.0 \%$ in the endurance group, $79.7 \%$ in the mixed sport group, $78.1 \%$ in the power sport group and $73.4 \%$ in the control group, respectively. In 1985, among endurance athletes, one participant had selfreported diabetes, and the corresponding numbers were six among the mixed sport group athletes, 12 among power sport athletes and 25 among controls, respectively.

The former endurance athletes were the oldest (Table 1); their mean (SD) birth year was 1926 (9.5), and that of the controls was $1932(8.9)(p<0.001)$. Most of athletes from the endurance group were white-collar workers, in the mixed

Table 1 Basic characteristics of the study population $(n=2174)$

\begin{tabular}{|c|c|c|c|c|}
\hline & Endurance $(n=228)$ & Mixed $(n=656)$ & Power $(n=430)$ & Controls $(n=860)$ \\
\hline Birth year [mean $(\mathrm{SD})]$ & $1926(9.5)$ & $1932(9.4)$ & $1930(9.3)$ & $1932(8.9)$ \\
\hline$p$ value* & $<0.001$ & 0.998 & 0.002 & \\
\hline \multicolumn{5}{|l|}{ Socio-economic status ${ }^{\mathrm{a}}$} \\
\hline Highly educated $^{\mathrm{b}}[n(\%)]$ & $27(12.1)$ & $261(40.7)$ & $55(13.1)$ & $90(11.3)$ \\
\hline White-collar workers $^{\mathrm{c}}[n(\%)]$ & $108(48.2)$ & $250(39.0)$ & $148(35.2)$ & $189(23.8)$ \\
\hline Blue-collar workers $^{\mathrm{d}}[n(\%)]$ & $54(24.1)$ & $117(18.3)$ & $185(43.9)$ & $341(42.9)$ \\
\hline Farmers, others or unskilled $[n(\%)]$ & $35(15.6)$ & $13(2.0)$ & $33(7.8)$ & $174(21.9)$ \\
\hline
\end{tabular}

$S D$ standard deviation

* Means are compared by one-way ANOVA and post hoc tests by Dunnett (compared to controls)

${ }^{a}$ Data available for 224 in the endurance group, 641 in the mixed group, 421 in the power group and 794 in the control group

b Management and professionals

c Experts, office workers and clerks

${ }^{\mathrm{d}}$ Service, sales, construction, repair, manufacturing, process and transport workers 


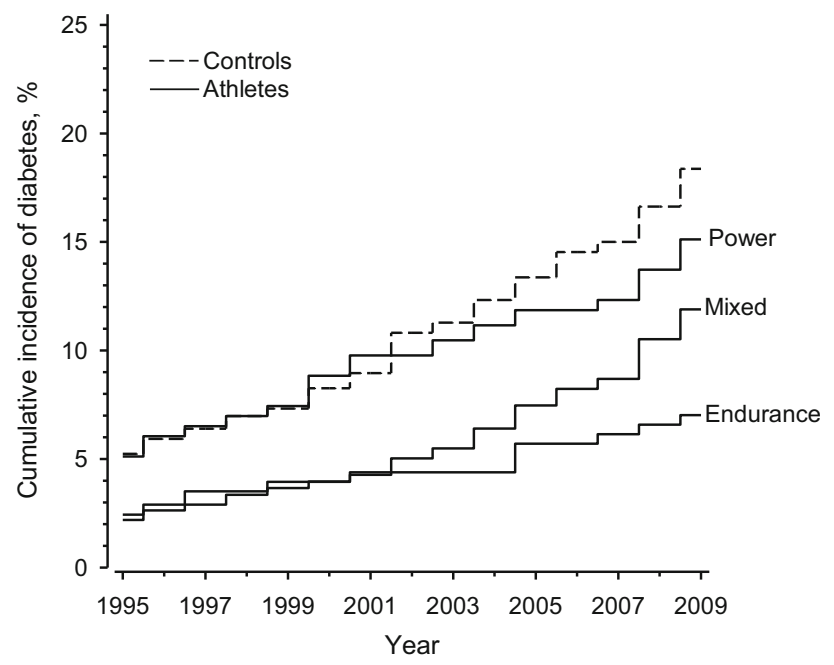

Fig. 2 Cumulative incidence of diabetes in different athletes and control groups. During the years 1995-2009, there were 16 new endurance athletes diagnosed with type 2 diabetes, 73 mixed group athletes, 48 power athletes and 135 controls, respectively

group highly educated, and in power and control group bluecollar workers, respectively (Table 1).

The cumulative incidence of diabetes between 1995 and 2009 was lowest in the endurance group (Fig. 2).

\section{Costs of diabetes medication}

Among all study subjects, the total cost of diabetes medication during the 15-year follow-up was significantly lower among the former athletes from the endurance group (mean $81 €[95 \%$ CI 33-151 €]), compared with the control group (mean $376 €$ [95\% CI $284-485 €]$ ), birth year adjusted $p<0.001$
(Table 2). Of the former endurance athletes, $0.4 \%$ used insulin, $3.5 \%$ of the mixed sport athletes, $6.3 \%$ of the power athletes and $5.2 \%$ in the controls, respectively, between endurance and control group birth year adjusted $p=0.018$. Among those study participants who had diabetes, the cost of insulin medication was significantly lower among the former athletes from the endurance group (mean $75 €$ [95\% CI 0-277 €]), compared with the control group (mean $917 €[95 \%$ CI 600-1309€]), birth year adjusted $p \leq 0.001$ (Table 2).

Among all study subjects, the former athletes from the endurance and mixed group had significantly lower total cost of diabetes medication per person years than the controls, differences between endurance and control group $p<0.001$, and between mixed and control group $p=0.045$, respectively (Fig. 3). However, among the study subjects with diabetes, no significant differences were observed for total cost of diabetes medication per person years between the groups ( $p=0.081$ ) (Fig. 3).

\section{Discussion}

The findings in this study show that a career as endurance, sprint, jumper or team game athlete mitigates the burden of cost of diabetes medication in later life. In particular, this is seen among the endurance athletes. Further, the use of insulin was extremely low among the former endurance athletes. However, restricting the analyses to subjects with diabetes attenuated the findings.

As far as we know, this is the first study evaluating the association between vigorous physical activity during young adulthood and the costs of diabetes medication in

Table 2 Costs of diabetes medication among all study subjects and the subjects with diabetes in different athletes and control groups

\begin{tabular}{|c|c|c|c|c|c|c|}
\hline & $\begin{array}{l}\text { Endurance } \\
(n=228)\end{array}$ & $\begin{array}{l}\text { Mixed } \\
(n=656)\end{array}$ & $\begin{array}{l}\text { Power } \\
(n=430)\end{array}$ & $\begin{array}{l}\text { Controls } \\
(n=860)\end{array}$ & $p$ value $^{1}$ & $\begin{array}{l}\text { Multiple } \\
\text { comparison }^{2}\end{array}$ \\
\hline Person years & 2434 & 7669 & 4685 & 9393 & - & - \\
\hline Number of diabetes $(\%)$ & $16(7.0)$ & $78(11.9)$ & $65(15.2)$ & $158(18.4)$ & & \\
\hline Total number of diabetes years & 79 & 432 & 362 & 822 & - & - \\
\hline \multicolumn{7}{|c|}{ Medication cost $(€)$ among all study subjects, mean $(95 \% \mathrm{CI})^{\mathrm{a}}$} \\
\hline Total & $81(33-151)$ & $272(181-388)$ & $393(256-592)$ & $376(284-485)$ & $<0.001$ & $\mathrm{M} / \mathrm{E}, \mathrm{P} / \mathrm{E}, \mathrm{C} / \mathrm{E}$ \\
\hline Oral diabetes medication & $76(31-136)$ & $134(91-183)$ & $161(104-232)$ & $207(160-268)$ & 0.016 & $\mathrm{C} / \mathrm{E}$ \\
\hline Insulin & $5(0-19)$ & $138(66-236)$ & $232(119-280)$ & $168(109-248)$ & $<0.001$ & $\mathrm{M} / \mathrm{E}, \mathrm{P} / \mathrm{E}, \mathrm{C} / \mathrm{E}$ \\
\hline \multicolumn{7}{|c|}{ Medication cost $(€)$ among subjects with diabetes, mean $(95 \% \mathrm{CI})^{\mathrm{a}}$} \\
\hline Total & $1157(608-1871)$ & $2288(1612-3128)$ & $2599(1845-3493)$ & $2045(1624-2510)$ & 0.028 & $\mathrm{P} / \mathrm{E}$ \\
\hline Oral diabetes medication & $1082(589-1693)$ & $1124(847-1450)$ & $1063(740-1467)$ & $1129(904-1381)$ & 0.99 & \\
\hline Insulin & $75(0-277)$ & $1163(606-1999)$ & $1536(818-2507)$ & $917(600-1309)$ & $\leq 0.001$ & $\mathrm{P} / \mathrm{E}, \mathrm{M} / \mathrm{E}, \mathrm{C} / \mathrm{E}$ \\
\hline
\end{tabular}

$E$ endurance, $M$ mixed, $P$ power, $C$ control

${ }^{1} p$ value between groups, adjusted for birth year

${ }^{2} p$ values (at significance level 0.05 ) for pairwise group comparisons adjusted for multiplicity using Hochberg's multiple comparison procedure

a $95 \%$ confidence intervals obtained by bias-corrected bootstrapping 

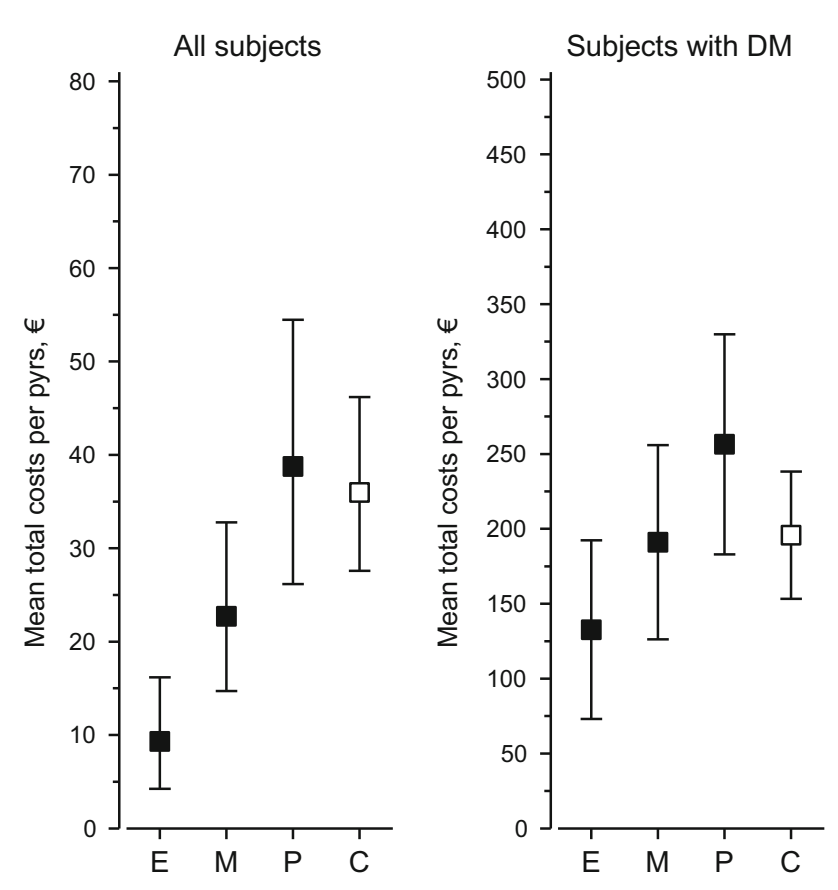

Fig. 3 Total costs of diabetes medication per person years (pyrs) in different athletes and control groups among all study subjects and the subjects with diabetes. Among all study subjects, the former athletes from the endurance and mixed group had significantly lower total cost of diabetes medication pyrs than the controls, differences between endurance and control group $p \leq 0.001$, and, respectively, between mixed and control group $p=0.045$. However, among the study subjects with diabetes, no significant differences were observed for total cost of diabetes medication for pyrs between the groups $(p=0.081)$. The whiskers represent $95 \%$ CI. $D M$ diabetes, $E$ endurance, $M$ mixed, $P$ power, $C$ controls, pyrs per person years

later life. Previous study findings from the Male Former Elite Athletes Study extending to the year 1998 have shown that the use of diabetes medication was remarkably low among endurance, sprint, jumper and team game athletes [21]. Furthermore, leisure-time physical activity levels among former elite-class endurance, sprint, jumper or team game athletes are typically higher than among the general population throughout the entire life course; however, this difference is not noticed between former eliteclass power athletes and the general population [15, 22]. Also differences in genetic factors between power sports athletes and other groups may explain the observed difference. Several lifestyle interventions studies aiming at prevention of type 2 diabetes have been focusing on middle-aged or older people, but the follow-up time of many of these intervention has been rather short [23]. Generally, lifestyle intervention consists of both diet and exercise counselling. Based on these studies, cost analysis has been made, including direct medical cost analysis, as well as modelling economic studies. According to these study findings, healthy lifestyle changes are cost-effective and the economic savings are bigger the earlier the counselling is initiated [24-27]. Further, an Australian study showed in middle-aged people with pre-diabetes that exercise counselling was the third most cost-effective treatment after metformin therapy and diet and exercise counselling when aiming at prevention and slowing down the onset of diabetes [28]. Among overweight and obese persons with type 2 diabetes, those who had an intensive lifestyle intervention seem to have fewer hospitalizations, use less medication and have lower health-care costs than those with common diabetes support and education [7]. These observations are in line with our study findings.

We found that endurance, sprint, jumper or team game athletes had a low cumulative incidence rate of type 2 diabetes. These results endorse previous study observations from the Male Former Elite Athletes Study, which have shown that a career as an elite-class athlete is associated with a low prevalence of diabetes [15, 22].

\section{What is behind the beneficial effects of regular physical activity?}

Various mechanisms underlie the favourable effects of regular physical activity on glucose regulation and consequently also reflecting on the use of glucose lowering medication. Physical activity has an important role in glucose-insulin metabolism [29-32]. During exercise training, there is an increase in skeletal muscle blood flow, recruitment of capillaries as well as in the expression and translocation of GLUT4-transporters [33, 34]. Increased GLUT4 expression is thought to enhance insulin sensitivity, glucose disposal and muscle glycogen storage [34, 35]. Further, people who do regular endurance-type training seem to have a higher proportion of type 1 muscle fibres, which have been associated with better insulin sensitivity $[36,37]$. Physical exercise also seems to be associated with better mitochondrial function, thus improving muscle insulin sensitivity [38]. Physical activity seems to reduce body mass index and waist circumference [39, 40]. However, the study findings in relation to physical exercise and fat content in the liver are not unequivocal, and both beneficial effect and no effect have been reported [41-43]. Another possible explanation is that regular physical activity during young adulthood works through an 'exercise memory effect'. Overall, physical activity seems to influence glucose metabolism via several pathways.

\section{Strengths of the study}

The study population is globally unique, and the cohort size of elite-class athletes is considerably large. The eliteclass athletes have a well-documented history of vigorous physical activity during young adulthood. Further, the register held by the Finnish Defence Force made it possible 
to select the matched controls among those Finnish men who were classified as healthy at the age of 20 years. Finally, the Finnish Social Insurance Institution upholds a comprehensive prescription register, which enables us to link the diabetes medications purchases including the costs with the study participants.

\section{Limitations of the study}

Information on study participants' glucose control was not available. If the glucose control is non-optimal, it may affect diabetes medication and consequently also the cost. Unfortunately, we were missing data on BMI and leisure-time physical activity from almost every fourth study participants. Although we found an association between former endurance-type sports participation and reduced need of diabetes medication, our study design did not allow definite analysis on how much of this association is explained by higher middle age or later life physical activity, which are higher among the former athletes than among the controls. Detailed information on sedentary habits or sleeping pattern was not available. All our participants were of European ancestry and men. Finally, the former elite-class athletes form a genetically selected group. Underlying genetic pleiotropy may explain some of the associations between becoming an eliteclass athlete, metabolic/aerobic fitness and later occurrence of metabolic disorders [44].

\section{Conclusions}

A career as endurance, sprint, jumper or team game athlete seems to reduce the costs of diabetes medication in later life. Among male former athletes, the use of insulin is rare.

\begin{abstract}
Acknowledgements We would like to thank the National Institute for Health and Welfare, Department of Public Health, University of Helsinki; Department of Health Sciences, University of Jyväskylä; Paavo Nurmi Centre, Turku and Orton Research Institute, Invalid Foundation, Helsinki for collaboration during the large epidemiological research programme.
\end{abstract}

Funding The study was funded by the Ministry of Education and Culture, the Juho Vainio Foundation, the Finnish Heart Research Foundation, the Paavo Nurmi Foundation, the Finnish Cultural Foundation and by a grant from Medical Society of Finland, Finska Läkaresällskapet.

Authors contribution All authors contributed to the development of the research, interpretation of the data, drafting of the manuscript and approved the final version. ML wrote the manuscript. RK worked up with the data. HK analysed the data.

\section{Compliance with ethical standards}

Conflict of interest The authors declare that they have no conflict of interest.
Ethical standards The ethics committee of the Hospital District of Helsinki and Uusimaa approved the study.

Human and animal rights All procedures followed were in accordance with the ethical standards of the responsible committee on human experimentation (institutional and national) and with the Helsinki Declaration of 1975, as revised in 2008.

Informed consent All participants have provided written informed consent.

\section{References}

1. International Diabetes Federation (2015) IDF Diabetes Atlas, 7th edn. Brussels, Belgium: International Diabetes Federation. http:// www.diabetesatlas.org. Accessed 27 Sept 2016

2. Helmrich SP, Ragland DR, Leung RW, Paffenbarger RS Jr (1991) Physical activity and reduced occurrence of non-insulindependent diabetes mellitus. N Engl J Med 325:147-152

3. Lynch J, Helmrich SP, Lakka TA et al (1996) Moderately intense physical activities and high levels of cardiorespiratory fitness reduce the risk of non-insulin-dependent diabetes mellitus in middle-aged men. Arch Intern Med 156:1307-1314

4. Pan XR, Li GW, Hu YH et al (1997) Effects of diet and exercise in preventing NIDDM in people with impaired glucose tolerance. The Da Qing IGT and diabetes study. Diabetes Care 20:537-544

5. Tuomilehto J, Lindstrom J, Eriksson JG et al (2001) Prevention of type 2 diabetes mellitus by changes in lifestyle among subjects with impaired glucose tolerance. N Engl J Med 344:1343-1350

6. Knowler WC, Barrett-Connor E, Fowler SE et al (2002) Reduction in the incidence of type 2 diabetes with lifestyle intervention or metformin. N Engl J Med 346:393-403

7. Espeland MA, Glick HA, Bertoni A, Look AHEAD Research Group et al (2014) Impact of an intensive lifestyle intervention on use and cost of medical services among overweight and obese adults with type 2 diabetes: the action for health in diabetes. Diabetes Care 37:2548-2556

8. Paffenbarger RS Jr, Jung DL, Leung RW, Hyde RT (1991) Physical activity and hypertension: an epidemiological view. Ann Med 23:319-327

9. Laine MK, Eriksson JG, Kujala UM et al (2014) A former career as a male elite athlete-does it protect against type 2 diabetes in later life? Diabetologia 57:270-274

10. Umpierre D, Ribeiro PAB, Kramer CK et al (2011) Physical activity advice only or structured exercise training and association with $\mathrm{HbA}_{1 \mathrm{c}}$ levels in type 2 diabetes. JAMA 305:1790-1799

11. McGinley SK, Armstrong MJ, Boule NG, Sigal RJ (2015) Effects of exercise training using resistance bands on glycaemic control and strenght in type 2 diabetes mellitus: a meta-analysis of randomised controlled trials. Acta Diabetol 52:221-230

12. Liubaoerjijin Y, Terada T, Fletcher K, Boule NG (2016) Effect of aerobic intensity on glycemic control in type 2 diabetes: a metaanalysis of head-to-head randomized trials. Acta Diabetol 53:769-781

13. Chacko E (2016) Timing, intensity and frequency of exercise for glucose control. Acta Diabetol. doi:10.1007/s00592-016-0886-5

14. Boule NG, Liubaoerjijin Y, Terada T (2016) Reply to Elsamma Chacko: " timing, intensity and frequency of exercise for glucose control". Acta Diabetol. doi:10.1007/s00592-016-0887-4

15. Balducci S, Vulpiani MC, Pugliese L et al (2014) Effect of supervised exercise training on musculoskeletal symptoms and function in patients with type 2 diabetes: the Italian Diabetes Exercise Study (IDES). Acta Diabetol 51:647-654 
16. Sarna S, Sahi T, Koskenvuo M, Kaprio J (1993) Increased life expectancy of world class male athletes. Med Sci Sports Exerc 25:237-244

17. Åstrand P, Rodahl K (1986) Physiological bases of exercise. In: Textbook of work physiology, McGraw Hill, New York, pp 412-415

18. WHO (2003) Introduction to drug utilization research. apps. who. int/medicinedocs/en/d/Js4876e/. Accessed 27 Sept 2016

19. Consumer price index (e-publication). ISSN $=1799-0254$. Helsinki: Statistics Finland. Available at: http://www.stat.fi/til/khi/ men_en.html. Accessed 27 Sept 2016

20. Classification of Occupations (2010). Available at: http://stat.fi/ meta/luokitukset/ammatti/001-2010/index_en.html. Accessed 27 Sept 2016

21. Kujala UM, Sarna S, Kaprio J (2003) Use of medications and dietary supplements in later years among male former top-level athletes. Arch Intern Med 163:1064-1068

22. Sarna S, Kaprio J, Kujala UM, Koskenvuo M (1997) Health status of former elite athletes. The Finnish experience. Aging (Milano) 9:35-41

23. Alouki K, Delisle H, Bermudez-Tamayo C, Johri M (2016) Lifestyle interventions to prevent type 2 diabetes: a systematic review of economic evaluation studies. J Diabetes Res. doi:10. $1155 / 2016 / 2159890$

24. Palmer AJ, Roze S, Valentine WJ, Spinas GA, Shaw JE, Zimmet PZ (2004) Intensive lifestyle changes or metformin in patients with impaired glucose tolerance: modeling the long-term health economic implications of the diabetes prevention program in Australia, France, Germany, Switzerland, and the United Kingdom. Clin Ther 26:304-321

25. Diabetes Prevention Program Research Group (2012) The 10-year cost-effectiveness of lifestyle intervention or metformin for diabetes prevention: an intent-to-treat analysis of the DPP/ DPPOS. Diabetes Care 35:723-730

26. Liu X, Li C, Gong H et al (2013) An economic evaluation for prevention of diabetes mellitus in a developing country: a modelling study. BMC Public Health. doi:10.1186/1471-2458-13-729

27. Saha S, Carlsson KS, Gerdtham UG et al (2013) Are lifestyle interventions in primary care cost-effective?-An analysis based on a Markov model, differences-in-differences approach and the Swedish Bjorknas study. PLoS ONE. doi:10.1371/journal.pone. 0080672

28. Bertram MY, Lim SS, Barendregt JJ, Vos T (2010) Assessing the cost-effectiveness of drug and lifestyle intervention following opportunistic screening for pre-diabetes in primary care. Diabetologia 53:875-881

29. Balducci S, Sacchetti M, Haxhi J et al (2014) Physical exercise as therapy for type 2 diabetes mellitus. Diabetes Metab Res Rev. doi:10.1002/dmrr.2514

30. Kujala UM (2011) Physical activity, genes, and lifetime predisposition to chronic disease. European review of aging and physical activity: $31-36$
31. Colberg SR, Sigal RJ, Fernhall B et al (2010) Exercise and type 2 diabetes: the American College of Sports Medicine and the American Diabetes Association: joint position statement executive summary. Diabetes Care 33:2692-2696

32. Yusuf S, Reddy S, Ounpuu S, Anand S (2001) Global burden of cardiovascular diseases: part I: general considerations, the epidemiologic transition, risk factors, and impact of urbanization. Circulation 104:2746-2753

33. Andersen P, Saltin B (1985) Maximal perfusion of skeletal muscle in man. J Physiol 366:233-249

34. Richter EA, Hargreaves M (2013) Exercise, GLUT4, and skeletal muscle glucose uptake. Physiol Rev 93:993-1017

35. Christ-Roberts CY, Pratipanawatr T, Pratipanawatr W et al (2004) Exercise training increases glycogen synthase activity and GLUT4 expression but not insulin signaling in overweight nondiabetic and type 2 diabetic subjects. Metabolism 53:1233-1242

36. Costill DL, Fink WJ, Pollock ML (1976) Muscle fiber composition and enzyme activities of elite distance runners. Med Sci Sports 8:96-100

37. Lundsgaard AM, Kiens B (2014) Gender differences in skeletal muscle substrate metabolism-molecular mechanisms and insulin sensitivity. Front Endocrinol. doi:10.3389/fendo.2014.00195

38. Phielix E, Meex R, Ouwens DM et al (2012) High oxidative capacity due to chronic exercise training attenuates lipid-induced insulin resistance. Diabetes 61:2472-2478

39. Aadahl M, Kjaer M, Jorgensen T (2007) Associations between overall physical activity level and cardiovascular risk factors in an adult population. Eur J Epidemiol 22:369-378

40. Philipsen A, Hansen AL, Jorgensen ME et al (2015) Associations of objectively measured physical activity and abdominal fat distribution. Med Sci Sports Exerc 47:983-989

41. Shojaee-Moradie F, Baynes KC, Pentecost C et al (2007) Exercise training reduces fatty acid availability and improves the insulin sensitivity of glucose metabolism. Diabetologia 50:404-413

42. Johnson NA, Sachinwalla T, Walton DW et al (2009) Aerobic exercise training reduces hepatic and visceral lipids in obese individuals without weight loss. Hepatology 50:1105-1112

43. van der Heijden GJ, Wang ZJ, Chu ZD et al (2010) A 12-week aerobic exercise program reduces hepatic fat accumulation and insulin resistance in obese, Hispanic adolescents. Obesity 18:384-390

44. Kujala UM, Jokelainen J, Oksa H et al (2011) Increase in physical activity and cardiometabolic risk profile change during lifestyle intervention in primary healthcare: 1-year follow-up study among individuals at high risk for type 2 diabetes. BMJ Open. doi:10. 1136/bmjopen-2011-000292 